\title{
Levelized Cost of Energy for a Backward Bent Duct Buoy
}

\author{
Diana Bulla,*, D. Scott Jenne ${ }^{\mathrm{b}}$, Christopher S. Smith ${ }^{\mathrm{c}}$, Andrea E. Copping ${ }^{\mathrm{d}}$, Guild Copeland ${ }^{\mathrm{a}}$ \\ ${ }^{a}$ Water Power Technologies, Sandia National Laboratories, Albuquerque, NM 87185 \\ ${ }^{b}$ Wind and Water Power Program, National Renewable Energy Laboratory, USA \\ ${ }^{c}$ Applied Researh Laboratory, Penn State University, State College, PA 16804 \\ ${ }^{d}$ Pacific Northwest National Laboratories, USA
}

\begin{abstract}
The Reference Model Project, supported by the U.S. Department of Energy, was developed to provide publically available technical and economic benchmarks for a variety of marine energy converters. The methodology to achieve these benchmarks is to develop public domain designs that incorporate power performance estimates, structural models, anchor and mooring designs, power conversion chain designs, and estimates of the operations and maintenance, installation, and environmental permitting required. The reference model designs are intended to be conservative, robust, and experimentally verified. The Backward Bent Duct Buoy (BBDB) presented in this paper is one of three wave energy conversion devices studied within the Reference Model Project. Comprehensive modeling of the BBDB in a Northern California climate has enabled a full levelized cost of energy (LCOE) analysis to be completed on this device.
\end{abstract}

Keywords: Wave Energy Converter, Oscillating Water Column, Levelized Cost of Energy, Backward Bent Duct Buoy, Reference Model Project, Marine Hydro-Kinetic

The Reference Models serve as non-proprietary open-source study objects for technical and economic evaluation. The US Deparment of Energy has supported the creation of a total of 6 Reference Models, the first four are detailed in [1]. Three of these reference models are current energy converters (CECs): a horizontal axis tidal turbine, a vertical axis riverine turbine, and a horizontal axis open-ocean current 5 turbine. Three of these reference models are wave energy converters (WECs): a floating 2-body point absorber, a pitching flap device, and a floating oscillating water column (OWC) device. The reference models are intended to provide a benchmark of technical and economic performance. The levelized cost of energy (LCOE), in dollars per kilowatt-hour $(\$ / \mathrm{kWh})$, was estimated for each Reference Model, including LCOE for a single device and arrays of 10, 50, and 100 units in order to quantify cost reductions associated with 10 economies of scale. The reference models also provide open-source designs with corresponding experimental data. The combination of these two intents has identified cost reduction pathways and research priorities for improving performance and reducing costs.

A Northern CA deployment climate, near Eureka, was selected as the reference wave energy resource 2. The deployment climate in which this device was analyzed is the same for all of the WEC Reference 15 Models. This site has an annual average incident wave power flux of $31.5 \frac{\mathrm{kW}}{\mathrm{m}}$.

A Backward Bent Duct Buoy (BBDB), shown in Fig. 1, is a floating OWC device composed of an Lshaped duct open to the ocean downstream from the wave propagation direction. The BBDB design was first proposed by Masuda [3] in the 1980s and is one variety of floating OWC devices. The incident waves result in a fluctuating pressure within the air-chamber. Bidirectional air flow drives the turbine and produces an electrical power output. The BBDB benefits from the coupled surge, heave, and pitch rigid-body modes and the OWCs resonance to expand the frequency range of efficient conversion [4].

\footnotetext{
* Corresponding author

Email addresses: dlbull@sandia.gov (Diana Bull), Dale.Jenne@nrel.gov (D. Scott Jenne), css27@arl.psu.edu (Christopher S. Smith), Andrea.Copping@pnnl.gov (Andrea E. Copping), gcopel@sandia.gov (Guild Copeland)
} 


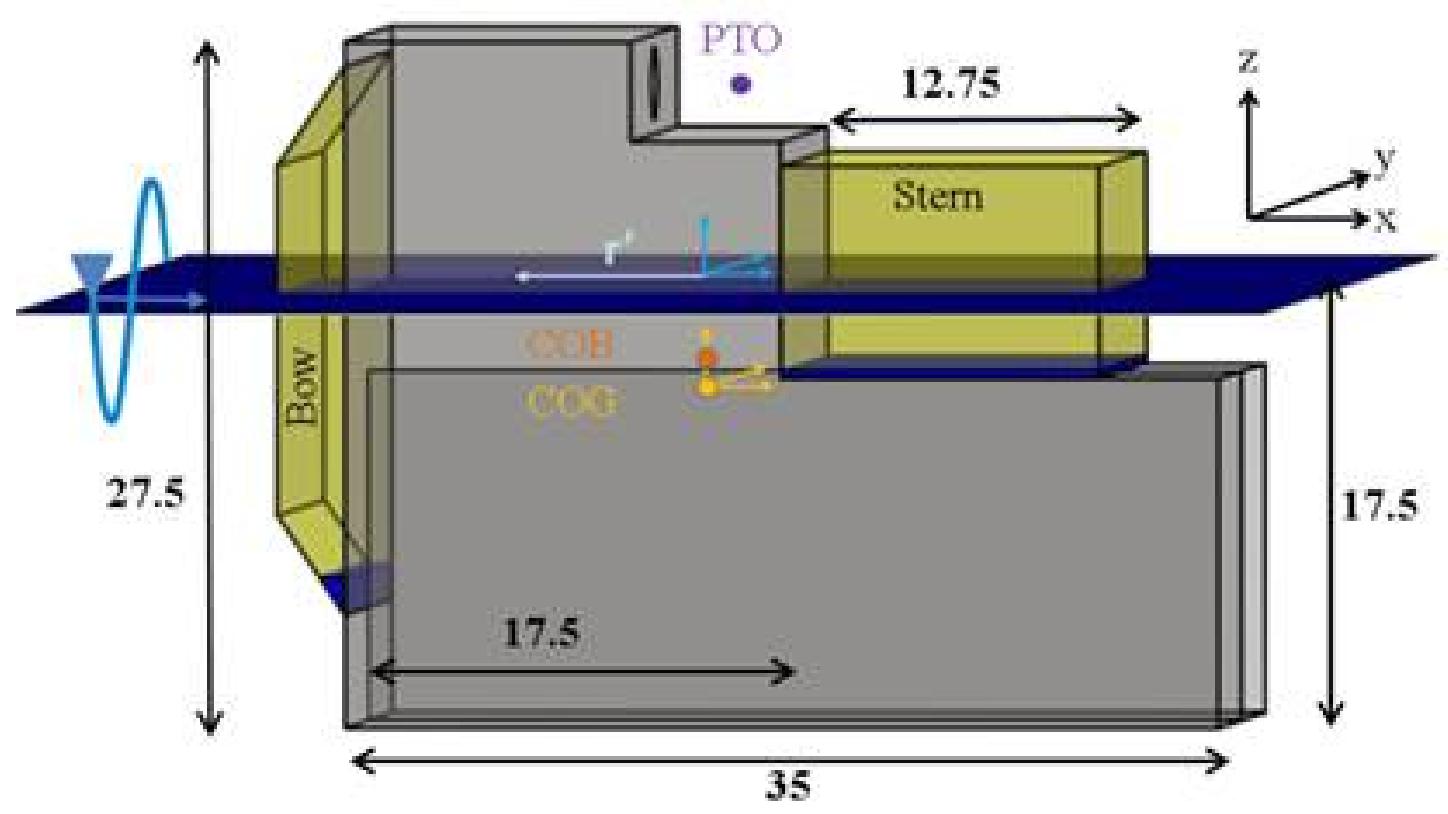

Figure 1: Reference Model 6: BBDB device design and dimensions (in meters). The width of the device (not shown) is $27 \mathrm{~m}$.

This paper presents an overview of the detailed technical analyses that were completed on the BBDB. These detailed analyses included the development of:

- pneumatic and electric performance models [4, 5] where a Wells Turbine was assumed,

- an anchor and mooring layout designed to withstand a 100-year storm in the climate [6],

- and a structural design [7].

The uncertainties associated with each of the technical analyses are highlighted as each is presented. Overviews of the operations and maintenance, installation, and environmental permitting are presented along with their uncertainties [2, 8].

These technical analyses facilitated the LCOE calculations assuming a 20-year operational life at multiple array scales [2]. This economic analysis is presented and the major cost drivers in this design are identified. Sensitivity analyses on key subsystems are presented to broaden the applicability of this work.

Due to the desire to have robust and conservative estimates, the LCOE should be viewed as a baseline. The modelling team has attempted to highlight areas of uncertainty associated with each of the analyses.

\section{Device Design}

\subsection{Mooring and Foundation}

The mooring system specifications are driven by the extreme sea states. In order to protect the Power Conversion Chain (PCC) of the device, the air chamber is assumed to be fully vented, thus the dynamics of the device are completely dictated by the structure's response. During severe weather conditions, the 40 devices diffraction parameter is approximately half of its wave height to characteristic length ratio which is a measure of the importance of the drag force 6. Therefore, the hydrodynamic forces on the device can be calculated using Morisons Equation 9]. This allows for the use of OrcaFlex, a time domain mooring line dynamics software, to analyze the performance of the BBDBs mooring system. 


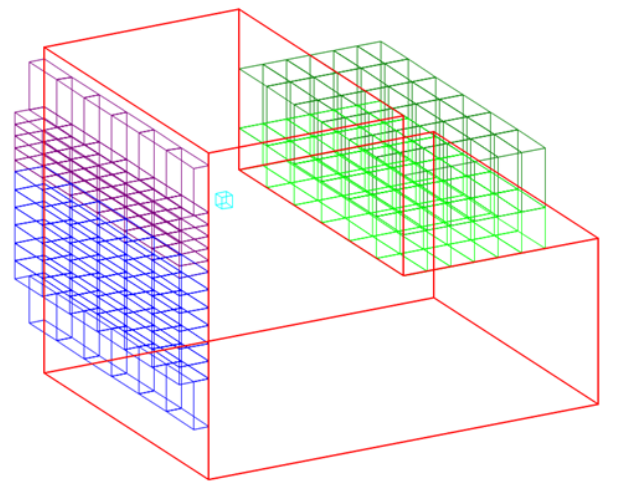

(a) Illustration of the buoyancy bodies

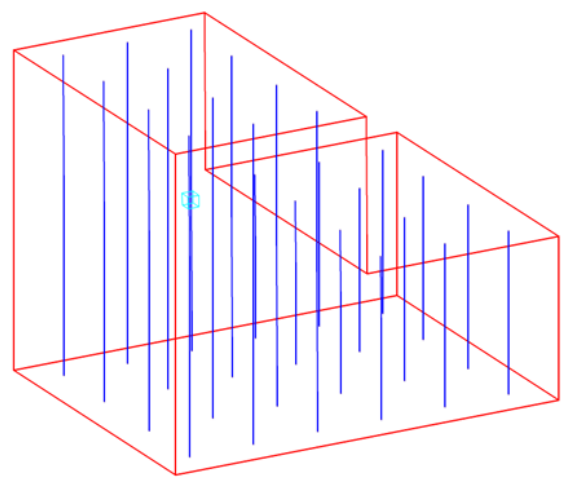

(b) Illustration of the freely flooding bodies

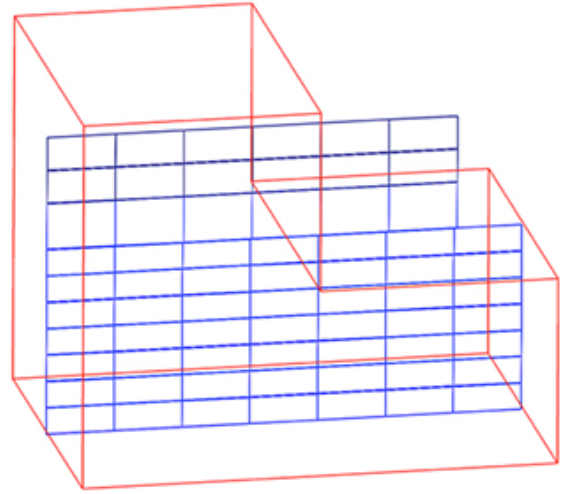

(c) Illustration of the hydrodynamic bodies in sway

Figure 2: Discretized bodies used in the OrcaFlex modeling.

The analysis in OrcaFlex was completed by developing an array of 6- Degree of Freedom (DOF) lumped bodies representing: structrual bodies to account for structural mass, inertia, and buoyancy distribution (Fig. 2(a) ; freely flooding bodies that account for the time-dependent variation of entrained water mass (Fig. 2(b) ; and hydrodynamic bodies that account for inertial and viscous effects (Fig. 2(c)). Separating individual responses allows for each to be treated independently and in a manner that is consistent with the phenomenon being modeled; for example the bodies representing the buoyancy distribution will not be assigned mass or hydrodynamic properties, they will only be assigned volumes. The baseline drag coefficients associated with each translational direction [surge, sway, heave] were $[1.2,1.2,5.0]$. The added mass was explicitly defined as a hemisphere of water with a radius defined by the overall lengths of the surface. The array of lumped bodies was then attached to a reference body that acts as the integrand of the loading effects. This representation resulted in the rotational response being controlled by the distribution and density of discrete bodies. More detailed explantations of this modeling approach can be found in [6].

The mooring was laid out to have two front lines separated by $60^{\circ}$ with the bisector of that angle being the operational incident wave direction and the aft line along the operational incident wave direction, see Fig. 3. Storm waves mostly arrive from a $-30^{\circ}$ direction from the operational wave direction, hence the majority of the storm load will affect one mooring leg.

Simulations of the device when subject to the extreme environment consisting of collinear waves, current, and wind (as specified by Det Norske Veritas (DNV) rules [10]) were completed in order to specify the mooring system. The sediment type at the deployment location was assumed to be soft clay, for all mooring 


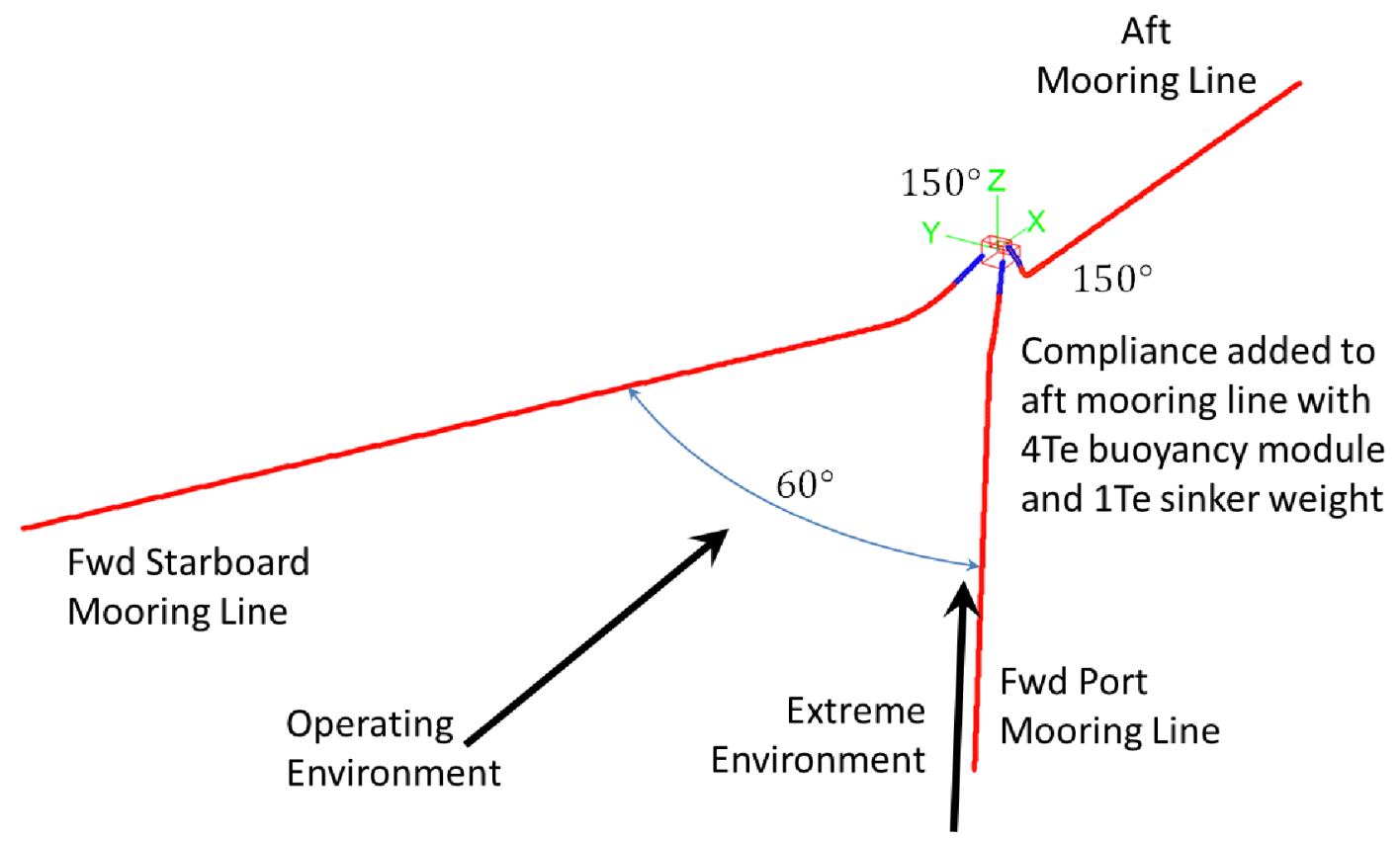

Figure 3: Mooring laoyout in the Northern CA climate.

simulations. Using the inverse FORM technique, the 100-year contour of significant wave height $\left(H_{s}\right)$ and peak period $\left(T_{p}\right)$ was generated to determine that the extreme environment: $H_{s}=11.2 \mathrm{~m}$ and $T_{p}=17.3 \mathrm{sec}$ [1]. To simplify the analysis a regular wave equivalent of the extreme environment $(\mathrm{H}=21.3 \mathrm{~m}, \mathrm{~T}=17 \mathrm{sec})$ was combined with a current profile linearly decreasing from $0.33 \frac{\mathrm{m}}{\mathrm{s}}$ and a constant wind profile of $29.6 \frac{\mathrm{m}}{\mathrm{s}}$ in these simulations. The simulation resulted in displacements in excess of $15 \mathrm{~m}$, a peak line load of $2205 \mathrm{kN}$, and anchor load of $2139 \mathrm{kN}$. This environment resulted in the mooring specification as outlined in Table 1 .

Table 1: Mooring specification for the BBDB device.

\begin{tabular}{l|l|l|l}
\hline Property & Details & Port & Starboard \\
\hline Total length [m] & device to anchor & 81 & 810 \\
Polyester length [m] & 12-plait, 137 mm OD & 45 & 45 \\
Chain length [m] & R4 Studlink, 58 mm OD & 765 & 765 \\
Declination Angle [ $\left.{ }^{\circ}\right]$ & & 122.8 & 122.8 \\
Line Length in Water Column [m] & & 137.5 & 137.5 \\
Initial Tension [kN] & & 110.4 & 110.4 \\
Anchor Location, $[x, y, z][\mathrm{m}]$ & from device center & 155 \\
Anchor Holding Load \& Mass & Stevpris Mk6 drag embed & $3300 \mathrm{kN}, 7 \mathrm{~T},-59.6]$ & {$[-705.4,401.38,-59.6]$} \\
BBDB Attachment Point, $[x, y, z][\mathrm{m}]$ & from device center & {$[-8.75,-13.25,-8.75]$} & $3300 \mathrm{kN}, 7 \mathrm{~T}$ \\
\hline
\end{tabular}

The simulations are sensitive not only to the environmental input (the specified extreme condition) but also to the model inputs (the hydrodynamic characteristics). Hence studies were completed to assess the sensitivity of the mooring specifications to the incident wave direction, incident wave definition, and the magnitude of the viscous losses [12. Through the use of a SWAN model [12] in which the storm waves were sent from a $600 \mathrm{~m}$ depth to a $40 \mathrm{~m}$ depth, it was shown that the incident extreme wave definition, including the directionality, was conservative (the significante wave height (Hs) droped from $11.22 \mathrm{~m}$ to $9.39 \mathrm{~m}$ and the 
direction moved towards $-20^{\circ}$ ). Since all simulations were run for this larger wave aligned predominantly with one line, all values will have a larger factor of safety (FoS).

However, the parameteric drag study showed that increasing the surge or sway drag coefficients (or decreasing the heave coefficient) would result in much larger mooring loads; loads that could cause the mooring system to fail if subject to the original simulation environment 12. As an example, if the surge drag coefficent is doubled the anchor holding load is exceeded and an insufficient FoS on the line; all case studies are detailed in $[12$.

Although the diffraction parameter is half the parameter used to assess the importance of the drag force, diffraction still could play a role in the models hydrodynamic characteristis. Hence accounting for the diffraction of the device would increase the accuracy of the results.

The design was found to act linearly for excursions of $\pm 5 \mathrm{~m}$ in the surge, sway, and heave directions (note: the extreme loads occured for displacements three times this linear value). The magnitudes of the linear restoring forces are: $55.5 \mathrm{kN}$ in surge, $6.1 \mathrm{kN}$ in sway, and $7.5 \mathrm{kN}$ in heave. These linear restoring forces are used in determining the performance of the BBDB.

\subsection{Structural Design}

Ideally the structure would be designed to withstand the dynamic loading resulting in an extreme environment and would possess the required buoyancy and surface area to result in the desired properties. The dynamic loading would be a combination of nonlinear dynamic pressure, green water (water on top of the structure), and/or slam loads from waves crashing on top of the structure or the structure hitting the surface of the water. However, all of these loads are highly nonlinear, and the tools to assess these loads (see RANS solvers, LAMP, AEGIR) are beyond the scope of the Reference Model project.

As a starting point, a design load that corresponded to the hydrostatic pressure with a green water depth of $6.0 \mathrm{~m}$ was applied to the entire structure 7 . The lowest point $(23.5 \mathrm{~m})$ was then used to uniformly design the structural requirements by defining a design pressure of $236.3 \frac{\mathrm{kN}}{\mathrm{m}^{2}}$. This design pressure was applied to the device, according to [13, to determine the appropriate girder and stiffener sizing for a plate thickness of $15.9 \mathrm{~mm}$. Using ASTM A36 steel (36ksi yield strength) it was found that the stiffeners should be spaced every $0.75 \mathrm{~m}$ with a length of $1.97 \mathrm{~m}$ and that the girders should be spaced every $1.97 \mathrm{~m}$ with a length of $4.5 \mathrm{~m}[7$.

Table 2: Rigid body and general properties of the BBDB device.

\begin{tabular}{l|l}
\hline Property, symbol & Value \\
\hline Displaced Mass & $2,024,657 \mathrm{~kg}$ \\
Structural Mass & $1,808,944 \mathrm{~kg}$ \\
Bow Ballast Mass & $22,072 \mathrm{~kg}$ \\
Stern Ballast Mass & $123,641 \mathrm{~kg}$ \\
Power Conversion Mass & $70,000 \mathrm{~kg}$ \\
Equilibrium Entrained Water Mass & $15,255,844 \mathrm{~kg}$ \\
Radii of Gyration, $\left[R_{x x}, R_{y y}, R_{z z}\right]$ & {$[12.5,14.3,14.5] \mathrm{m}$} \\
COG, $\left[x_{z_{G}}, y_{z_{G}}, z_{z_{G}}\right]$ & {$[0,0,-4.29] \mathrm{m}$} \\
COB, $\left[x_{B}, y_{B}, z_{B}\right]$ & {$[0,0,-3.31] \mathrm{m}$} \\
Surface Area of Water Column & $473 \mathrm{~m}^{2}$ \\
Center of Surface Area of Water Column, $[x, y, z]$ & {$[-5.12,0,0] \mathrm{m}$} \\
Linear $( \pm 5 \mathrm{~m})$ mooring spring constant, $[x, y, z]$ & {$[55.46,6.10,7.48] \frac{\mathrm{kN}}{\mathrm{m}}$} \\
\hline
\end{tabular}

This structural design has been further simplified into a ASTM A36 steel design with an average wall thickness of $35.1 \mathrm{~mm}$ and a center bulkhead thickness of $46.7 \mathrm{~mm}$. The ballast is distributed to obtain the desired draft and ensure that the center of gravity and the center of buoyancy are aligned vertically. The 
ballast is assumed to be seawater and is added to the buoyancy chambers as shown in Fig. 1. The mass of the power conversion chain (drivetrain, generator, power conditioning electronics) is approximated and is placed at the expected center of the Wells Turbine location, shown as a point labeled PTO in Fig. 1 . Table 2 summarizes the structural properties of the device and Table 3 details the natural resonances of the device given these structural properties.

Table 3: BBDB natural resonance periods.

\begin{tabular}{l|c}
\hline Degree of freedom & Natural period (s) \\
\hline Surge & 149.5 \\
Heave & 16.1 \\
Pitch & 11.6 \\
Coupled OWC & 8.61 \\
\hline
\end{tabular}

Although simplistic, this severe hydrostatic loading has been shown to be, at a minimum, a factor of 10 larger than the dynamic survival loads obtained for Reference Model 3 (RM3, a 2-body point absorber) 7. Additionally, the peak line load from the mooring simulation, see Section 1.1, was evaluated using SolidWorks at the appropriate atttachment location and only minimal changes to the fundamental structure were required to wihtstand the mooring load [7. Hence, these two facts combine to indicate that the basic structure is very conservatively designed.

\subsection{Pneumatic Performance}

The wave-to-pneumatic converter is designed to capture the most available power from the incident waves. This is dictated mainly by the physical structure and the controls (implemented through the power conversion chain) used to influence the dynamics of the physical structure. The wave activated physical structure is hydrodynamically coupled to the oscillating water column contained within as both absorb power from the incident climate. There are two governing equations: one for the oscillating structure and one for the fluctuating air-pressure. The power conversion chain links the oscillating structure to the OWC through a resistive damping term $R_{\text {load }}$.

Table 4: Description of device state terms.

\begin{tabular}{|c|c|}
\hline uncol & $\begin{array}{l}\text { the structure is not hydrodynamically coupled to the water column, i.e. a grounded } \\
\text { OWC }\end{array}$ \\
\hline coupled & $\begin{array}{l}\text { the structure is wave activated and hence hydrodynamically coupled to the water } \\
\text { column, i.e. a floating OWC }\end{array}$ \\
\hline unlinked & $\begin{array}{l}\text { the power conversion chain is not influencing the dyanmics of the device, i.e. the air } \\
\text { chamber is fully vented }\end{array}$ \\
\hline linked & $\begin{array}{l}\text { the power conversion chain is linearly (in this case) influencing the dynamics of the } \\
\text { device through the selected control strategy values }\end{array}$ \\
\hline
\end{tabular}

A linear, frequency-domain performance model developed in three dimensions is used to predict the pneumatic performance of the device [4, 14]. This model links the oscillating structure to the air-pressure fluctuations with a linear control strategy in which pressure is proportional to flow. An array of field points defines the interior free surface allowing for hydrodynamic parameters relating to the fluctuating air-pressure within the BBDB to be calculated using reciprocity relations [4]. The hydrodynamic properties of the wave activated structure and the interior free surface were obtained through the potential flow solver WAMIT 15. 
As described more fully in [4] the coupled governing equations of motion that describe the body velocities $\dot{\boldsymbol{\xi}}$ and pressure fluctuations $p$ when subject to an incident wave of amplitude $\zeta$ are repeated here in Eq. 1 .

$$
\left[\begin{array}{c}
\mathbf{f}_{\text {exe }} \\
q_{\text {exe }}
\end{array}\right] \zeta=\left[\begin{array}{cc}
\mathbf{Z}_{i} & -\mathbf{h}_{i} \\
\mathbf{h}_{i} & Y_{i}+\frac{1}{R_{\text {load }}}
\end{array}\right]\left[\begin{array}{l}
\dot{\boldsymbol{\xi}} \\
p
\end{array}\right]
$$

The hydrodynamic excitation force $\mathbf{f}_{\text {exe }}$ and flow $q_{\text {exe }}$ are found directly through WAMIT. The intrinsic

radiation of the structure, $\mathbf{Z}_{i}$, includes the hydrodynamic radiation impedance as well as the viscous losses, hydrostatic resoration, and the mooring restoring forces. The viscous losses have been chosen to decrease the heave motion Response Amplitude Operator (RAO) to a reasonable value, somewhere around 3. The coupling term $\mathbf{h}_{i}$ connects body movements and pressure fluctuations; i.e. the moving body inducing pressure fluctuations and visa versa. The intrinsic radiation of the internal free surface, $Y_{i}$, includes the hydrodynamic radiation admittance as well as the viscous losses and the compressibility of the air flow. Lastly, the control strategy is implemented through $R_{\text {load }}$ resulting in the final relationship between the volume flow through the turbine and the pressure fluctuations:

$$
Q_{T}=q_{\text {exe }} \zeta-Y_{i} p-\mathbf{h}_{i}^{\mathrm{T}} \dot{\boldsymbol{\xi}}=\frac{p}{R_{\text {load }}} .
$$

As first shown in [4, more fully described in [16, and later verified experimentally [17] (see Section 1.3.1), the effect of hydrodynamically coupling the structures motions to the water column is the migration of the water column natural resonance frequency, even when the air chamber is fully vented to atmosphere. This can be readily seen by inspecting Eq. 2, when fully vented the pressure term is zero yet the coupling term remains, hence the migration of the water column natural resonance. The total hydrodynamic flow and its resonance frequency are influenced by both the magnitude of the coupling term (driven by the total surface area) and the number of rigid body modes through which coupling occurs.

The optimal linked performance of the BBDB in regular waves is shown in Fig. 4. The analytic expression for the optimal resistive damping shown in Fig. 4(a) compared with the numeric optimization, was first derived and presented in 4 . Since both the rigid-body motions and the free surface are accounted for in the derivation of $R_{l, o p t}$, the profile identifies multiple distinct minima corresponding to structural resonances for the coupled device. The structural resonances (heave, ptich and CoupledOWC) are identified with solid vertical lines while the peaks in $R_{l, o p t}$ are identified with dashed lines. These lines are repeated in Fig.'s 4(b), 4(c), and 4(d). From Fig. 4(b) it is clear that when the system is fully vented (the unlinked data), the structures dynamics are dictated by the structural resonances. However when the device is subject to linear control (the linked data) the dynamics shift towards having peak responses at peak $R_{l, \text { opt }}$ values. These characteristics are repeated in Fig.'s' 4(c) and 4(d).

The monochromatic BBBD performance model must be expanded to understand how the device will respond to random waves. Since the response of the device is linear, the spectral response of the device will follow the spectrum describing the incident climate. In order to transform from monochromatic to spectral response, relevant RAOs and the wave spectrum $S(\omega)$ that the device will be subject to are required. The optimal $R_{\text {load }}$ for each sea state, assuming only one $R_{\text {load }}$ can be applied for the duration of the sea state, is found through numeric optimization and is shown in Fig. 5

The response spectrum $S_{R}$ for any variable $R$ can then be obtained through 18

$$
S_{R}(\omega)=R A O(\omega)^{2} S(\omega) .
$$

The response spectrum will have units of (response unit) ${ }^{2}$-time (i.e. $\mathrm{Pa}^{2}-\mathrm{s}, \mathrm{N}^{2}$-s, etc.). Relevant statistical parameters can be calculated from the variables spectral density; for instance the root-mean-square (RMS), as shown in Eq. 4, can be calculated for any variable $R$,

$$
R_{R M S}=\sqrt{\int S_{R}(\omega) d \omega}=\sqrt{m_{0}} .
$$

Long-term performance estimates for a device are obtained by combining results from the spectral treatments with the probability of that spectrum occuring (given in a Joint Probability Distribution (JPD)) 
for the deployment site. For instance the average annual pressure $(A A p)$ for the device can be obtained according to Eq. 5 .

$$
A A p_{R M S}=\sum_{i, j} J P D_{i j} p_{R M S_{i j}},
$$

This procedure can be followed to obtain annual estimates of any variable: annual significant flow, annual RMS pressure, annual RMS pitch angle, etc. Table 5 highlights some of the average annual estimates of dynamic parameters when subject to $R_{\text {load }}$ 's as defined in Fig. 5 .

Table 5: BBDB average annual dynamic responses in random waves.

\begin{tabular}{l|c}
\hline Variable & Average Annual RMS \\
\hline Pressure & $2728 \mathrm{~Pa}$ \\
Flow & $66.2 \frac{\mathrm{m}^{3}}{\mathrm{sec}}$ \\
Heave & $0.43 \mathrm{~m}$ \\
Pitch & $2.9^{\circ}$ \\
\hline
\end{tabular}

\subsubsection{Experimental Verification}

Experiments were conducted at HMRC at University College Cork in Ireland. More detailed information can be found in [17. The device was tested using Froude scaling with a scaling factor of 50. The device (FSE) were tracked in three dimensions with a Qualisys system. Two measurements of the FSE were made within the chamber, one on the port side and one on the starboard (stbd) side. The derivative of the FSE measurements multiplied by the surface area can be used to estimate the volume flow through the representative power take off. Alternatively, since the representative power take off has been well calibrated, only the measurment of the pressure is needed and calibration curves can be used to derive the volume flow. A pressure sensor recorded the pressure inside of the air chamber.

A period sweep of regular small amplitude waves was run at the scaled device. For the hydrodynamically uncoupled case, the device was situated in a forward facing manner and was placed on cement blocks to obtain a reasonable draft. Since this is an uncoupled case, the resonant frequency of the chamber should not be affected by the forward facing orientation. For the hydrodynamically coupled case, the device was situated in a backward facing manner, secured with two mooring lines, and ballasted to obtain the desired draft.

Fig. 6(a) shows full scale experimental results for a hydrodynamically uncoupled (i.e. grounded) but linked BBDB with a $R_{\text {load }}=25 \frac{\mathrm{Pasec}}{\mathrm{m}^{3}}$. Since the dynamics of the structure do not influence the water column, the largest response is located at the expected 'piston' resonance location as illustrated in Fig. 6(a) The experimental volume flow RAO match's the model prediction magnitude and shape. The volume flow RAO was derived from both the starboard FSE measurements (triangles) as well as the calibration data (circles). When the calibration data is used, the pressure measurement is divided by the calibrated $R_{\text {load }}$ to obtain the volume flow. Given this low damping, [17 has shown this last method to be reliable.

Fig. 6(b) shows selected full scale results for a hydrodynamically coupled, unlinked BBDB. In this case, the dynamics of the structure do influence the water column, as given in Eq. 2, and thus the water column resonance has migrated to a new location, i.e. there is no evidence of $\omega_{\text {piston }}=0.46 \frac{\mathrm{rad}}{\mathrm{sec}}$ in the experimental data. The new resonance location is identified in Fig. 6(b) as well as the structural resonance locations. The experimental volume flow RAO matches the model prediction profile.

Since the numerical model presented in Section 1.3 is using assumed viscous losses as well modeling the air compressibility in the air chamber, it is not expected that a strong match in magnitude would be achieved. At model scale, there is no compressibility in the air chamber. However, the experimental data is able to verify the theoretical profiles in both the hydrodynamically uncoupled and coupled cases. 
At large radial frequencies, the predicted and experimentally determined values begin to diverge in all of the comparisons. However, the statistics reveal a large standard deviation resulting in a large error. Further, due to internal sloshing and higher order modes the measured FSE presents unreliable measurements in some cases. 


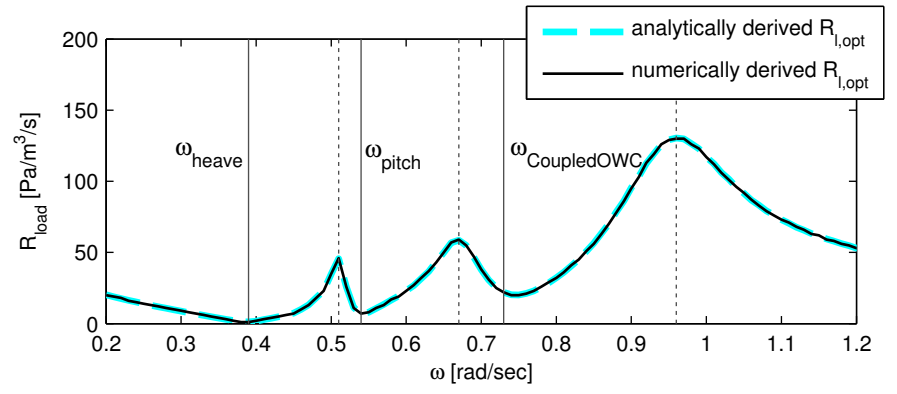

(a) Comparison of analytically derived and numerically obtained optimal resistive damping $R_{\text {load }_{\text {opt }}}$ for the BBDB.

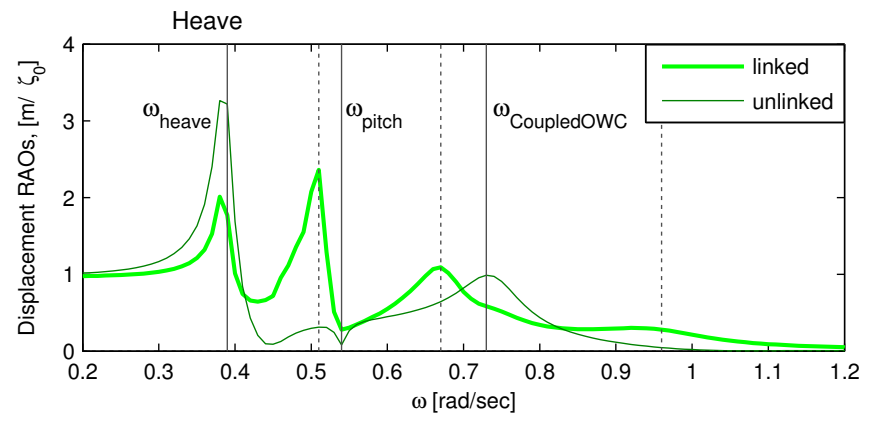

(b) RAO for heave with $R_{\text {load }_{o p t}}$ applied in the linked case and no control strategy in the unlinked case.

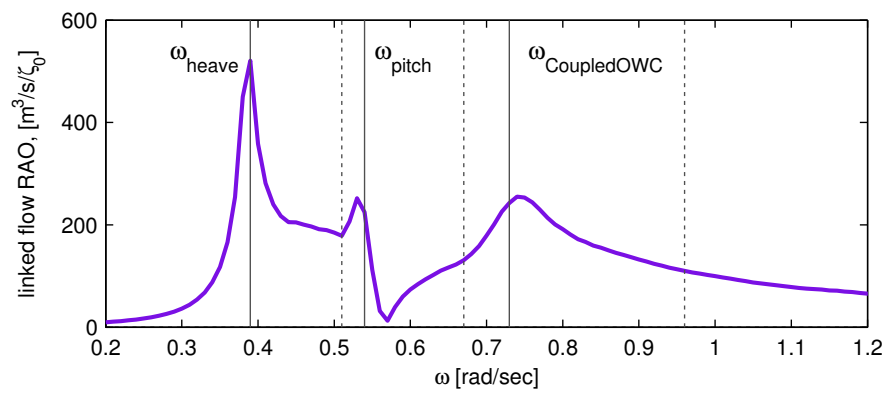

(c) RAO of relative linked flow with $R_{\text {load }}$ apt applied.

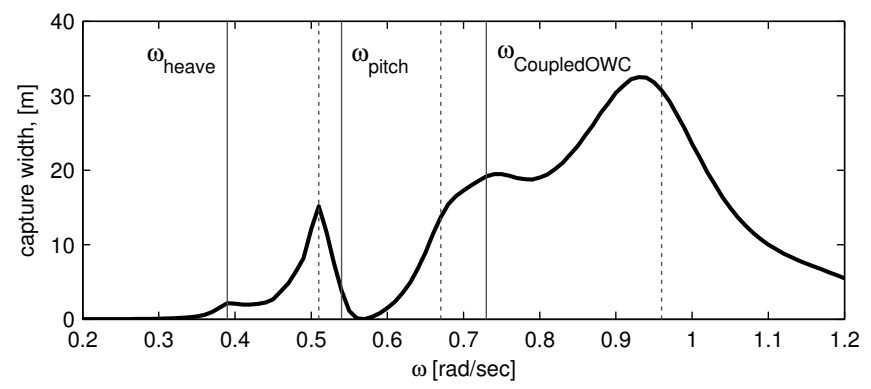

(d) Capture width with $R_{\text {load }}$ apt applied at each frequency.

Figure 4: Predictions of the BBDB in regular waves. 


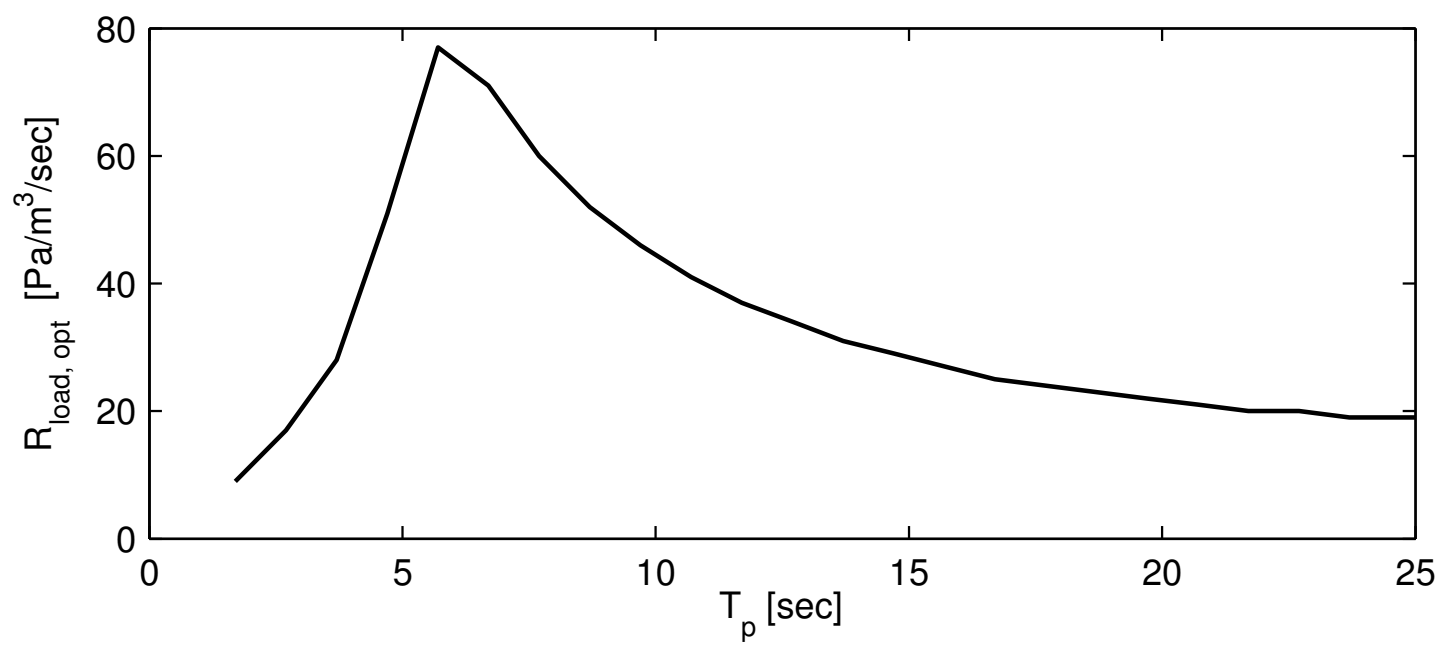

Figure 5: Optimal $R_{\text {load }}$ for each peak period $T_{p}$ specifing a Bretschneider sea state. 


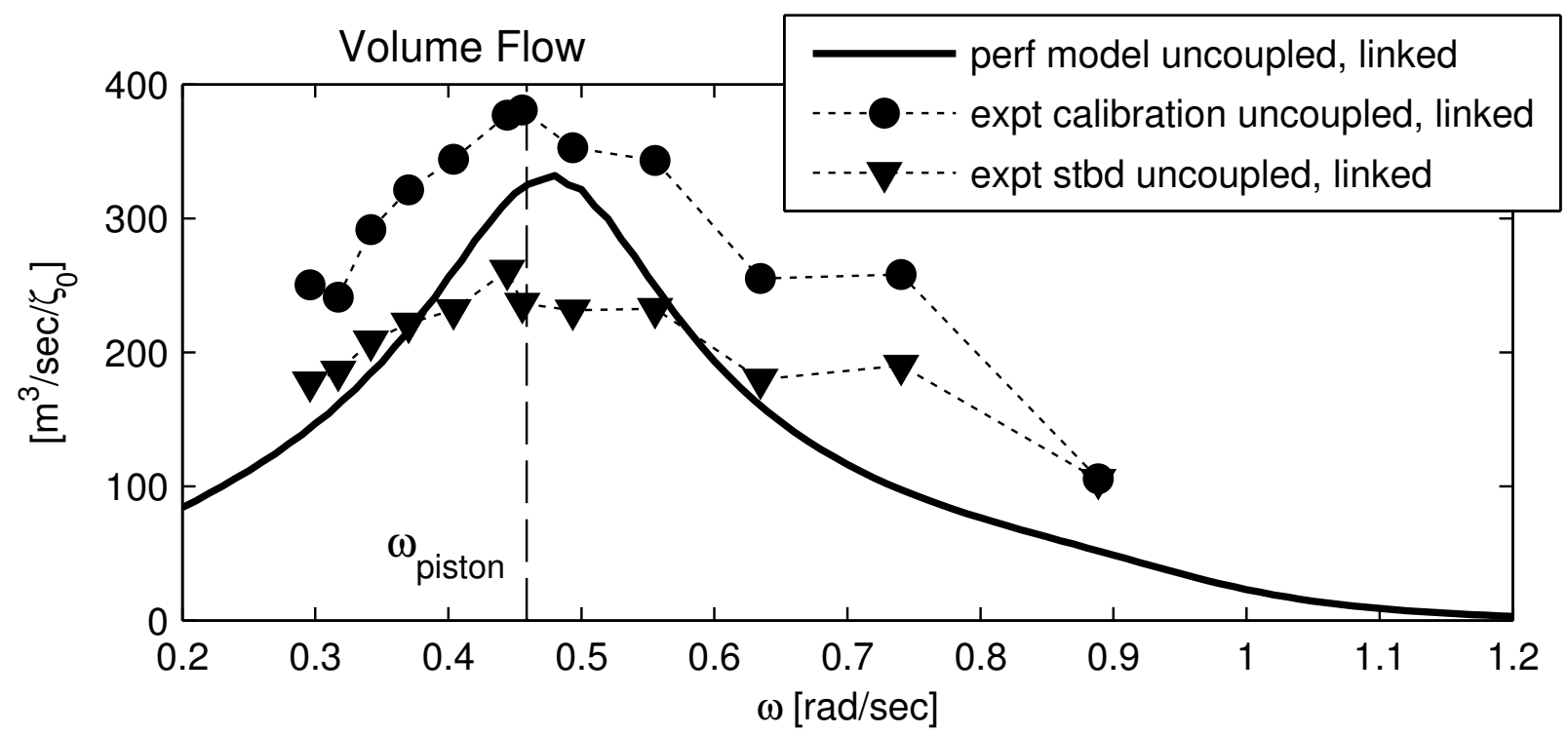

(a) Experimental volume flow vs. theoretical predictions for a hydrodynamically uncoupled but linked BBDB.

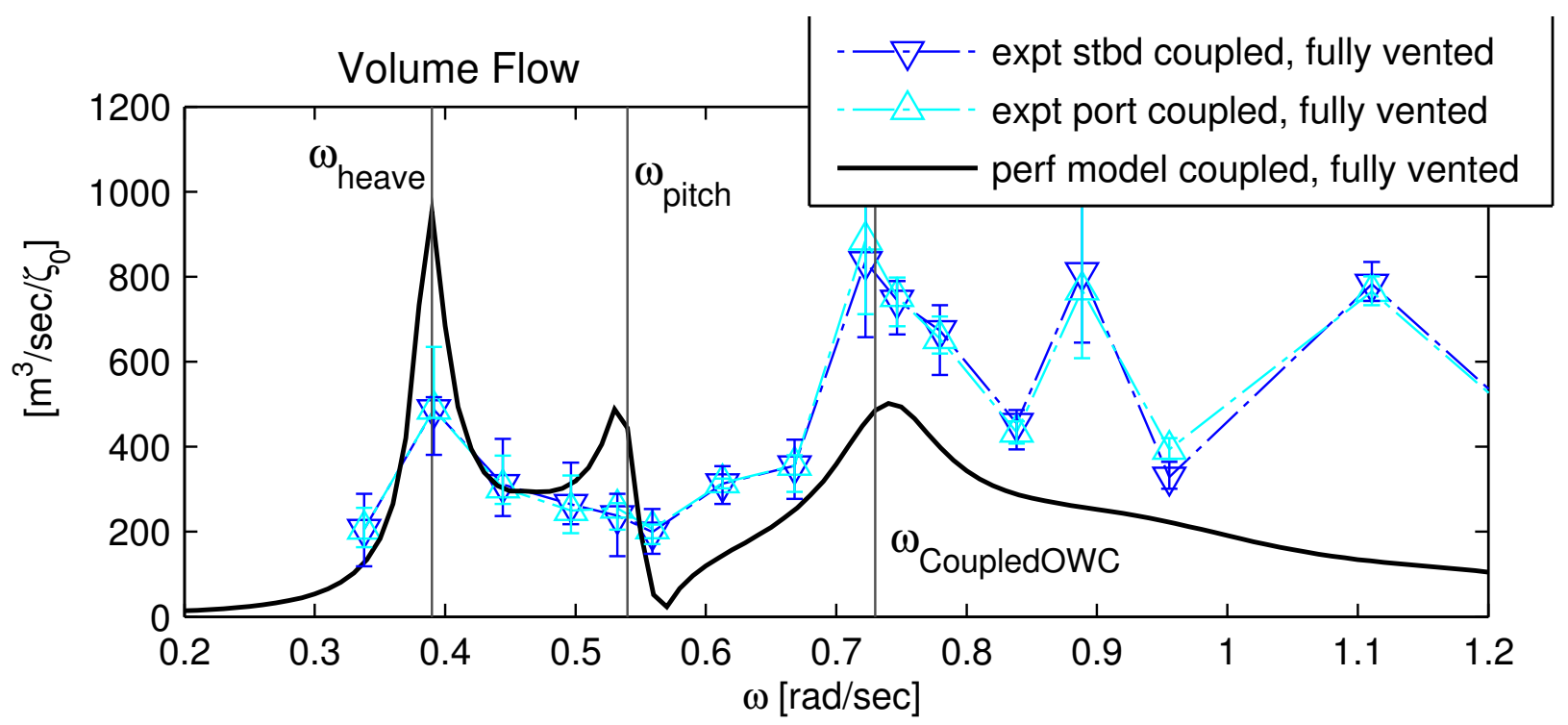

(b) Experimental volume flow vs. theoretical predictions for a hydrodynamically coupled but unlinked BBDB.

Figure 6: Volume flow vs. predictions and experimental data for no (or little) linking when hydrodynamically uncoupled (i.e. grounded) and coupled (i.e. floating). 


\subsection{Power Conversion Chain Design}

The BBDB performance model optimizes the pneumatic power available to the PCC. The pneumatic power is then converted to electrical power by use of an air turbine connected to an electric generator. A Wells turbine is capable of collecting power in a bi-directional flow and possess a linear relationship between pressure and flow, hence it was assumed in the PCC design. The Wells turbine consists of a fixed number of blades, which typically have a symmetric airfoil profile, and which have the blade chord oriented perpendicular to the rotational axis of the rotor. Although the Wells turbine works in bi-directional flow, it operates at peak efficiency for a relatively narrow range of flow coefficients [19, 20, 21, 22, as shown in Fig. 7. Obtaining optimum flow coefficients can be achieved by using chamber pressure relief valves [20] and by controlling the turbine RPM, which physically controls the $R_{\text {load }}$, for a fixed turbine diameter. The Wells Turbine choice is no longer predominant in industry since the peak value and bandwidth of the efficiency is known to be inferior to other turbines 23 .

In addition to the drivetrain, a PCC is composed of a generator, power electronics, and potentially short-term storage. A Variable Frequency Drive (VFD) has been chosen to condition the power. Further, the VFD is capable of altering the speed at which the turbine rotates, thus allowing for variable $R_{\text {load }}$. No short-term storage was modeled for this device.

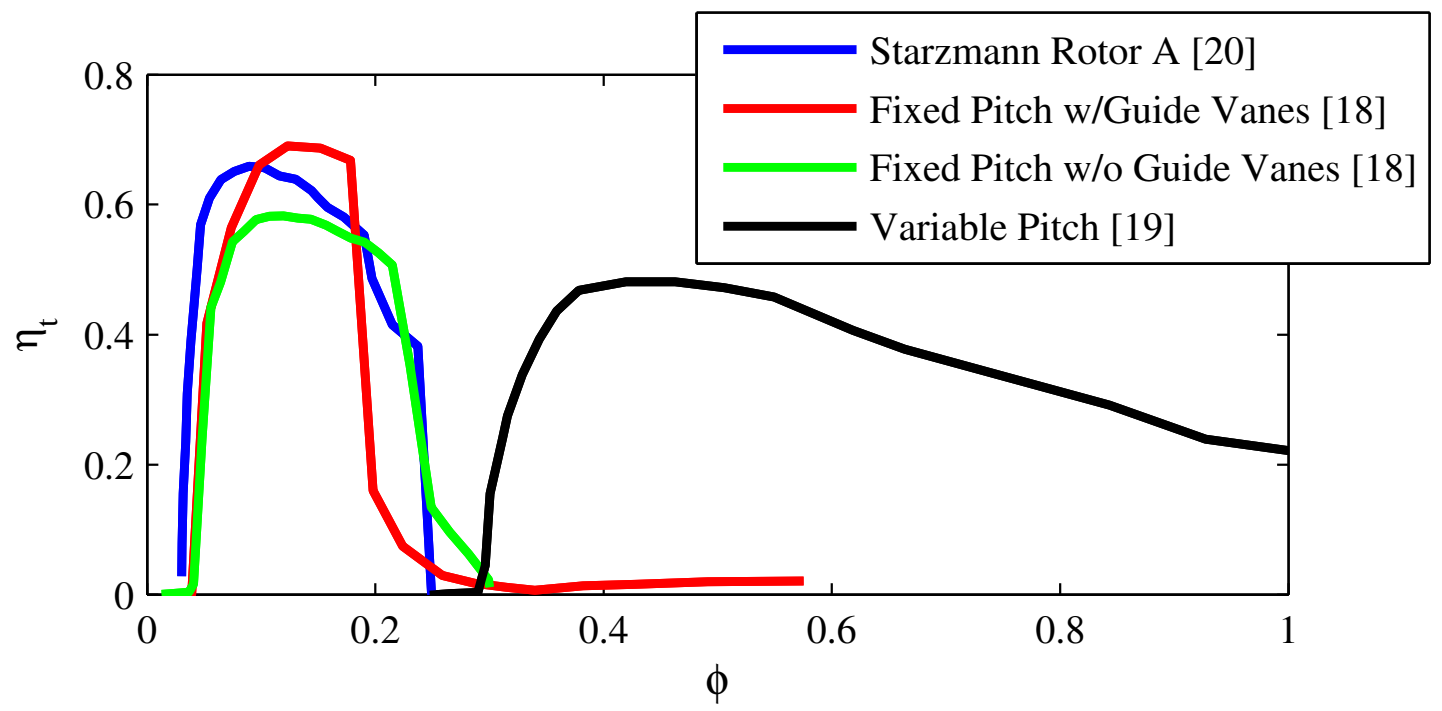

Figure 7: Wells turbine efficiency vs. flow coefficient for various turbine designs.

A number of design studies were conducted which attempted to locate the optimum PCC design for the provided BBDB design [24, 5]. These studies included variation of the turbine type, the vent pressure, the turbine radius, the number of turbines, and the power ratings of the VFD and generator. The pneumatic power is represented by the RMS pressure and volume flow rate predictions for each sea state in the wave climate, see Eq. 4. The PCC optimization then uses the sea state RMS values in combination with experimental Wells Turbine efficiency values to optimally size the turbine. The pneumatic power is then decremented by the Wells Turbine efficiency for each sea state and the new power value is then used to determine the combined generator and VFD efficiency. Since the RMS pressure and flow are used, this method applies only one efficiency value for each of the PCC components in a given sea state regardless of the fact that a given sea state contains a distribution of pressure and flow values (a full stochastic analysis can be seen in [25]). This methodology is repeated for each sea state in the JPD as opposed to using a single sea state to optimize the PCC selection. The average annual pneumatic (absorbed), mechanical, and electrical power (AAP, AAMP and AAEP respectively) are then calculated based on the JPD for the deployment location. In this way the designer is able to accommodate the full complexity of the deployment climate in 
the Wells turbine and power electronics selection.

In these studies, the turbine tip radius was varied between $0.1-2 \mathrm{~m}$, vent pressure was varied between 100 $10,000 \mathrm{~Pa}$, while the generator was varied between $75-373 \mathrm{~kW}$ and the VFD was varied between $75-746 \mathrm{~kW}$.

The RPM, $n$ in $\frac{r e v}{s e c}$, required to achieve the optimal $R_{l o a d}$ shown in Fig. 5 is found through

$$
\begin{gathered}
n=\frac{\phi R_{\text {tip }}}{\psi \rho_{a}} R_{\text {load }} \text { where } \\
\psi=\frac{\Delta p}{\rho_{a} U^{2}} \text { and } \\
\phi=\frac{U}{\omega R_{\text {tip }}}=\frac{Q_{T}}{\frac{\pi^{2}}{4} D^{3} n} .
\end{gathered}
$$

Above the flow coefficient $\phi$, turbine tip radius $R_{\text {tip }}$, non-dimensional pressure head coefficient $\psi$, density of air $\rho_{a}$, mean axial velocity $U$, turbine rotational speed $\omega$ in $\frac{\mathrm{rad}}{\mathrm{sec}}$, and turbine tip diameter $D$ are all needed to complete the calculations. With the flow coefficient known, the turbine efficiency $\eta_{t}$ can be obtained through the curves shown in Fig. 7. The generator $\eta_{g e n}$ and VFD $\eta_{V F D}$ efficiency curves are populated from standard sources [26, 27. It is important to note that while a generator can maintain high efficiency values when overloaded, the VFD can only output power up to its power rating. As a result any excess power put into the VFD is dumped out of the system, causing a steep decline in efficiency when the VFD is overloaded.

These studies have shown the interplay between turbine size, vent pressure, VFD power rating and generator power rating is complex. The final design is specified in Table 6 and a representation of the full PCC assembly is shown in Fig. 8

Table 6: PCC specification for the BBDB device.

\begin{tabular}{l|l|l}
\hline Part & Details & Size \\
\hline Turbine Rotor & Starzmann A, 5 bladed & $1.588 \mathrm{~m}$ \\
RPM & controlled by VFD & $400-1350$ \\
Vent Pressure & passive vents & $5380 \mathrm{~Pa}$ \\
Generator & Baldor IDDRPM404006; 460V, 460A & $298 \mathrm{~kW}$ \\
VFD & ABB - acs800-17-0580-5+C129 & $373 \mathrm{~kW}$ \\
\hline
\end{tabular}

Exercising the final design in the model results in the power performance outlined in Table 7 . Given the electrical power, $103 \mathrm{~kW}$, and the device rating, $373 \mathrm{~kW}$, this device has a capacity factor of 27.6.

Table 7: BBDB average annual power performance at each conversion step in random waves.

\begin{tabular}{lll}
\hline Variable & $\begin{array}{l}\text { Average } \\
\text { nual }\end{array}$ & $\begin{array}{c}\text { An- } \\
\text { Percent } \\
\text { Decrement }\end{array}$ \\
\hline $\begin{array}{l}\text { Pneumatic Power, } \\
P=p_{R M S} Q_{T, R M S}\end{array}$ & $208 \mathrm{~kW}$ & - \\
$\begin{array}{l}\text { Mechanical Power, } \\
M P=P \eta_{t}\end{array}$ & $115 \mathrm{~kW}$ & $44.7 \%$ \\
$\begin{array}{l}\text { Electrical Power, } \\
E P=M P \eta_{g e n} \eta_{V F D}\end{array}$ & $103 \mathrm{~kW}$ & $10.3 \%$ \\
\hline
\end{tabular}




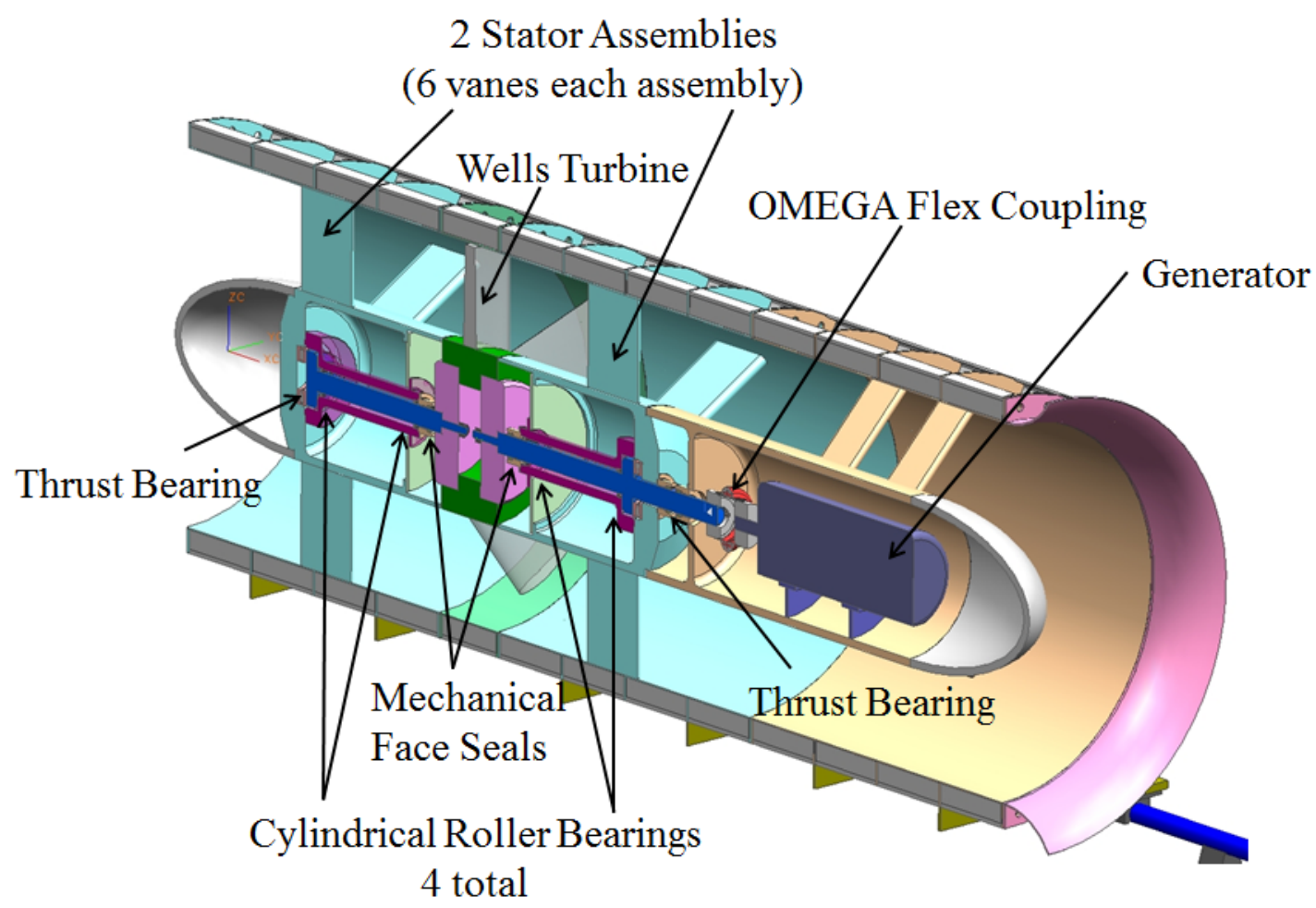

Figure 8: Representation of the full PCC assembly including supporting subcomponents.

Although this optimization procedure was quite advanced in its use of the full JPD, a fully stochastic model that accounted for the distribution of flow coefficients, and hence a distribution of mechanical conversion efficiency values, within a sea state would result in a more accurate, and likely lower, electrical power estimate. Further, $R_{\text {load }}$ should be optimized based upon maximum electrical power output, as opposed to pneumatic power output as was done in this analysis. Lastly, future work should include effects of compressibility on the turbine performance in the BBDB stochastic model.

\section{Installation and Infrastructure}

The deployment strategy for the BBDB is similar to that prescribed for RM3 [1. It accounted for the installation of the 1) mooring system, 2) subsea cable infrastructure, and 3) the devices themselves (including commissioning). This analysis assumed two of the DP-2 class vessels that ReVision specified for the RM3 installation to account for the significant mass of the BBDB and the mooring components. The BBDB is assumed to be mobilized from the Gulf of Mexico and the two DP-2 vessels would be required for 74 days in order to install a single device along with its mooring components.

A separate cable installation vessel is assumed to be used for installing the 3-phase AC cable rated at $30 \mathrm{kV}$. In this analysis, a total of 19 days were required to complete the cable install for a single device. It is assumed that horizontal drilling would be needed at the cable shore landing.

A single O\&M vessel would be used to connect the device to the mooring components in a single day. 


\section{Operations and Maintenance}

The requirements for the O\&M vessel were: 1) sufficient deck space to handle mooring lines and cable repair; 2) dynamic positioning (DP-1) to allow for more effective operation; and 3) crane lifting capacity of $5 \mathrm{Mg}$ at a 20 -foot radius. A 10-person crew, approximately, was required to operate the vessel and carry out repair and maintenance activities. Operations were assumed to take place only during daylight hours (12 hours per day) and the vessel would return to port at night.

Failure rate approximations for the Wells Turbine were made from the report by 28. The L-50 life was assumed to be the mean-time of the subsystem requiring complete replacement. Only components that would not require complete device retrieval were considered for replacement. The cost of replacement parts was assumed to equal the value of the part/subsystem of the original device.

No formal analysis was completed to estimate failure rates for other subsystems on the device. It was assumed that there would be one failure per year requiring the device to be retrieved.

Based on the failure rate assumptions and operational frequency, it was found that the device would require a total of two interventions per year. There are two major types of interventions: those requiring device recovery and those requiring only PCC recovery. The vessel day rates are different for the interventions; the rate is higher for device retrieval. Similar to installation, it is assumed that device retrieval would require two O\&M vessels.

Insurance estimates, assessed annually, were made as a percentage of the summation of Infrastructure, Mooring/Foundation, Device Structure, PCC, Subsystem Integration, and Installation costs. It is assumed that for single and 10-unit deployment insurance is $2 \%, 1 \%$ for 50 -units, and $0.5 \%$ for 100 -units.

A more stringent and formal analyis on the failure rates should be executed to increase the vailidity of these operations and maintenance estimates. It is expected that as the number of units within the array grows, experience and small adjustments will decrease the number of interventions; this is not reflected in the current analysis.

\section{Environmental Compliance}

Responsible deployment of marine energy devices in estuaries, coastal areas, and major rivers requires that biological resources and ecosystems be protected through siting and permitting (consenting) processes. Scoping appropriate deployment locations, collecting pre-installation (baseline) and post-installation data all add to the cost of developing Marine Hydro-Kinetic (MHK) projects, and hence to the levelized cost of energy. The logic models that describe studies and processes for environmental siting and permitting are detailed within [8, 29. The logic models and all costing information are separated into four stages: regulatory and administrative processes, siting and scoping, pre-installation assessment, and post-installation monitoring.

Specific environmental concerns for the BBDB include: the very large superstructure that may act as an attraction to birds, resulting in injuries and mortality due to the birds flying into the freeboard; the air turbine above the water may have acoustic impacts (105-140 dB) on marine mammals and birds or potentially present a nuisance to recreational users of the area; the presence of large air chambers within the device could potentially present an entrainment risk to fish, marine mammals, sea turtles, or diving birds; and finally, sections of mooring lines lying on the seafloor may present a greater risk to habitat from dragging while sections in the water column may present a risk of fishing gear entanglement, that may in turn endanger fish, marine mammals, diving birds, sea turtles and some invertebrates. Also, an array of $50+$ devices would require a significant footprint. Greater site dimensions are likely to increase the area of potential environmental effects and drive higher survey and monitoring costs.

In this analysis key assumptions are made regarding the pre-installation study durations for specific types of receptors. These assumptions are summarized in Table 8

\section{Levelized Cost of Energy}

The LCOE was calculated according to [30]. Specifically, the uniform financial parameters (such as tax, inflation, and project financial structure) were conformed to in the analysis. The fixed charge rate (FCR) 
Table 8: Examples of pilot scale study assumptions.

\begin{tabular}{l|l}
\hline Receptors & Data Collection Duration \\
\hline marine mammals & 1 year baseline \\
fish and invertebrates & 2 years baseline \\
birds & 1 year baseline \\
sea turtles & 1 year baseline \\
\hline
\end{tabular}

(the annual return needed to meet investor revenue requirements) assumed in this analysis is 0.108. The standardized finanacial variables are detailed in Table 9. Two of these parameters, the depreciation tax shield (D) and FCR, are derived from the choice of the financial variables in Table 9

Table 9: Standardized finanacial variables.

\begin{tabular}{lll}
\hline Symbol & Variable & Standard Value \\
\hline $\mathrm{r}$ & Real discount rate & 0.07 \\
$\mathrm{i}$ & Inflation rate & 0.025 \\
$\tau$ & Composite federal-state tax & 0.396 \\
& rate & \\
& Depreciation schedule & \\
& & MACRS \\
$\mathrm{D}$ & Present value of depreciation & 5 -Year Property \\
& tax shield & 0.309 \\
$\mathrm{~N}$ & project economic life & \\
$\mathrm{FCR}$ & fixed charge rate & 20 years \\
\hline
\end{tabular}

Assuming these financial parameters and relying heavily on previous cost estimates from RM3 [1], the expenditures for the BBDB could be assessed. The detailed spreadsheet that contains all cost breakdowns and calculations can be publically accessed through the Reference Model website 31. For each cost category, an attempt is made to identify the location of the data source as well as clarifying notes when applicable.

Highlights of the analysis are reproduced here. The cost breakdown structure, as presented in 30, is used. The development category includes the environmental siting and permitting as well as project design. Infrastructure includes the subsea cable and connectors as well as the costs of dedicated O\&M vessels as the size of the array increases. Mooring and foundation includes the costs of the mooring lines, anchors, connecting hardware, and supplemental buoyancy. The device structural components include both the cost of the source material as well as the fabrication. The PCC includes all aspects of the PCC detailed in Fig. 8. Subsystem integration acknowledges the need to assemble the individually listed components above. Installation and decommissioning cover the installation and removal of the device, mooring, subsea cable, and connections between the three. However, decommissioning is not included in the final LCOE calculation. Contingency was assumed at $10 \%$ of the project cost and is set aside to cover missing miscellaneous items. Profit was also assumed at $10 \%$ of the project cost and is included with subsystem integration.

Table 10 lists, in 2014 US dollars, the capital expenditures associated with a single BBDB. As demonstrated, the development and structural components are significant drivers in the single design case. However, when the array size is increased to 100 units, the device structural components have a greater impact on the capital expenditures at 56\% while the development costs drop to less than 4\%. Fig. 9 evaluates the capital expenditures' contribution to LCOE as a function of the deployment scale.

Fig. 10 evaluates the operational expenditures' contribution to LCOE as a function of the deployment 
Table 10: Capital expenditures required for for a single device deployed as a single unit.

\begin{tabular}{l|l|l}
\hline CapEx Category & $\mathbf{2 0 1 4}$ US dollars & Percent of Total \\
\hline Development & $\$ 5,205,000$ & $16.5 \%$ \\
Infrastructure & $\$ 1,111,000$ & $3.5 \%$ \\
Mooring/Foundation & $\$ 835,150$ & $2.6 \%$ \\
Device Structural Components & $\$ 7,682,500$ & $24.4 \%$ \\
PCC & $\$ 1,637,250$ & $5.2 \%$ \\
Subsystem Integration & $\$ 932,000$ & $3.0 \%$ \\
Installation & $\$ 5,908,500$ & $18.7 \%$ \\
Decomissioning & $\$ 5,908,500$ & $18.7 \%$ \\
Contingency & $\$ 2,331,150$ & $7.4 \%$ \\
\hline
\end{tabular}

scale. The post-installation environmental montoring is nearly a constant cost, hence as the number of units increases the dominance of this aspect decreases quickly.

Fig. 11 evaluates the LCOE as a function of the deployment scale. The dominant cost in the LCOE relates

\section{Conclusion}

A full overview of the BBDB Reference Model was presented in this paper. The detailed technical analyses relating to the mooring, structure, performance, and PCC were highlighted. The analyses relating to installation, O\&M, and environmental permitting for the BBDB off the Northern CA coast were also presented. This technical work was utilized in the full LCOE analysis presented at the end of the paper.

The LCOE presented is intended to be conservative. Both conservative and aggressive aspects of the assumptions made in the technical analyses were highlighted throughout the paper.

All information presented in this paper relating to the BBDB is publically available at the Refernce Model website [31. 


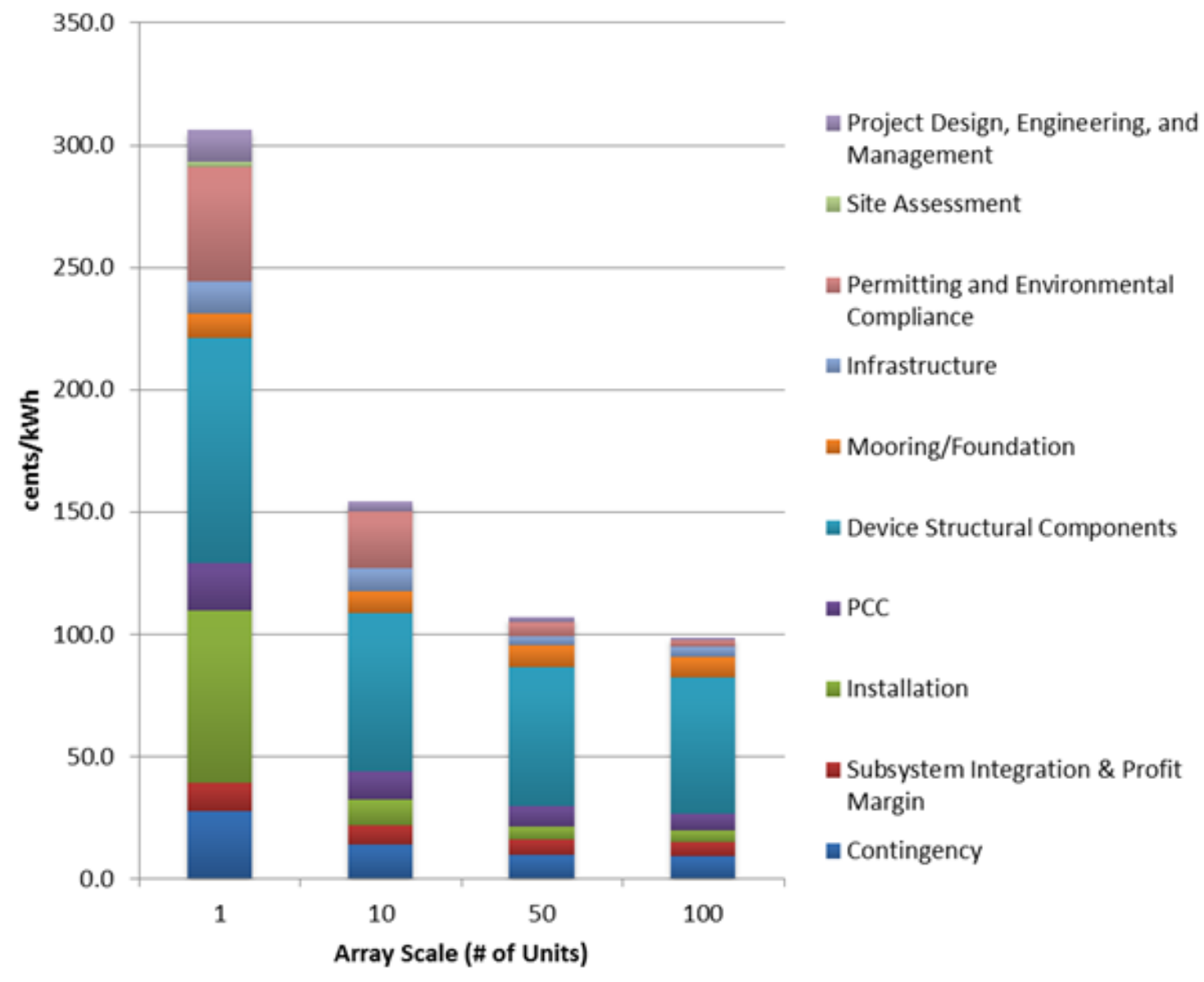

Figure 9: CapEx contributions to LCOE (cents/kWh) per deployment scale. 


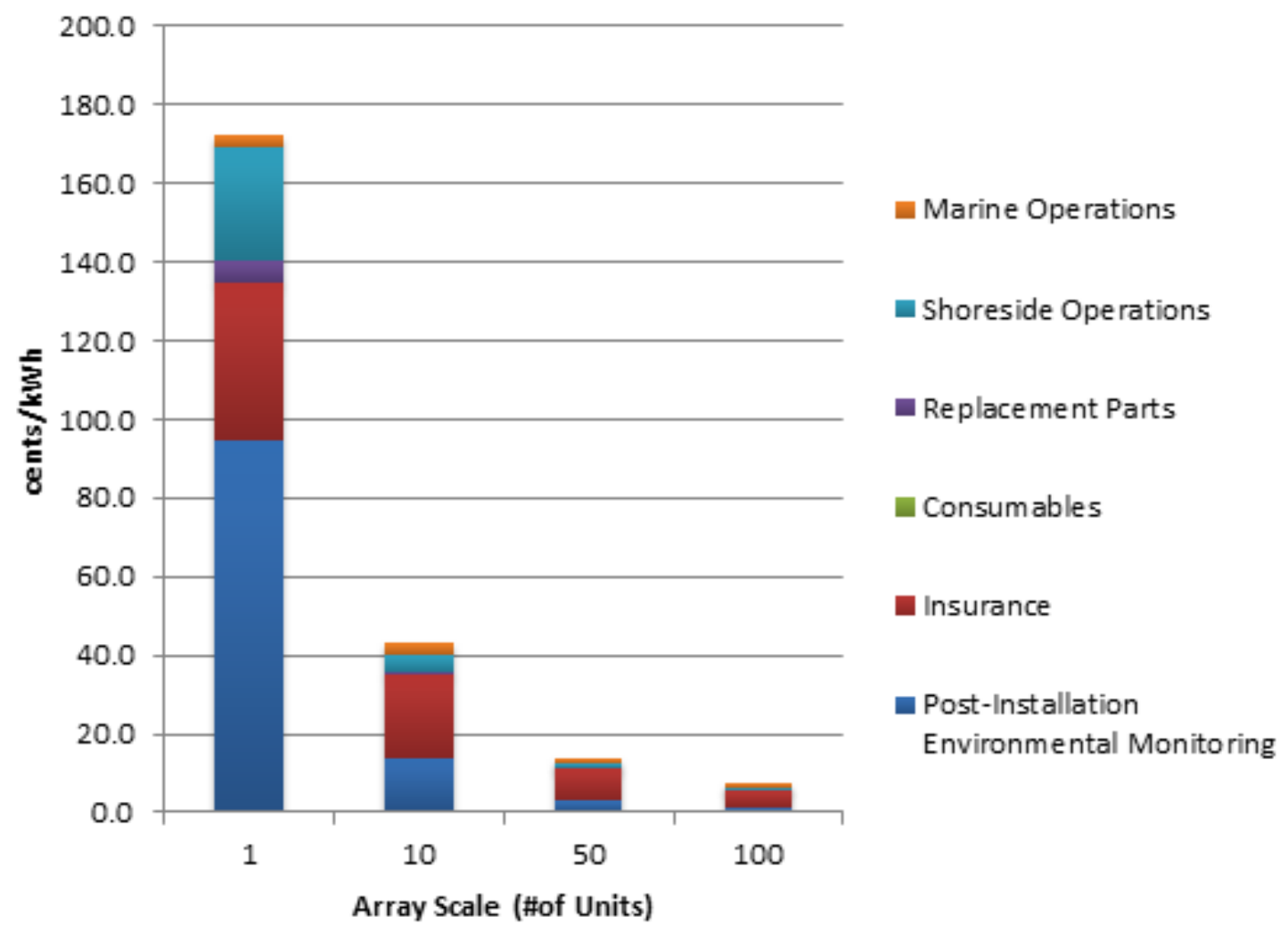

Figure 10: OpEx contributions to LCOE (cents/kWh) per deployment scale. 


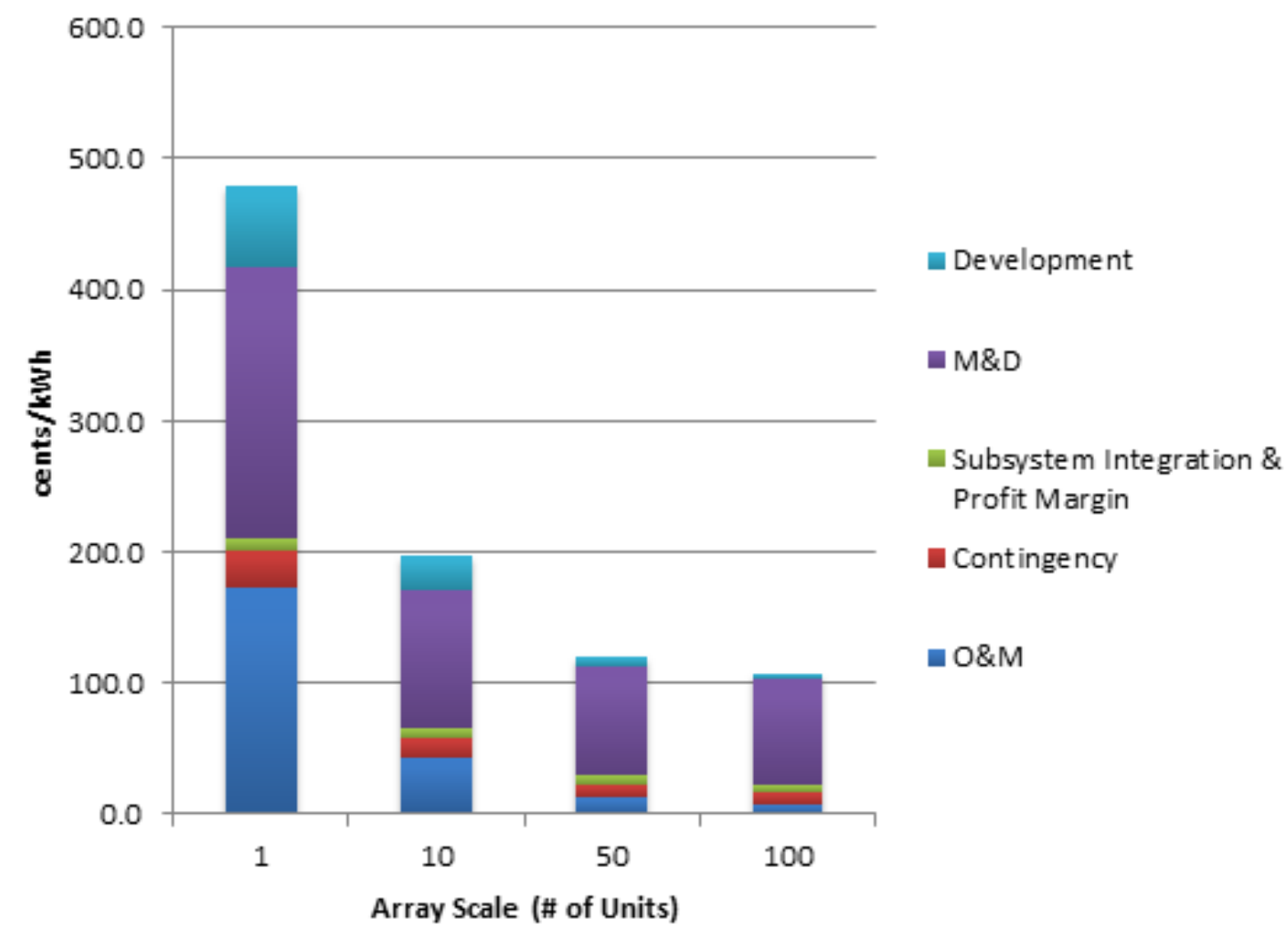

Figure 11: LCOE (cents/kWh) per deployment scale.

\section{LCOE Uncertainty (10-unit scale)}

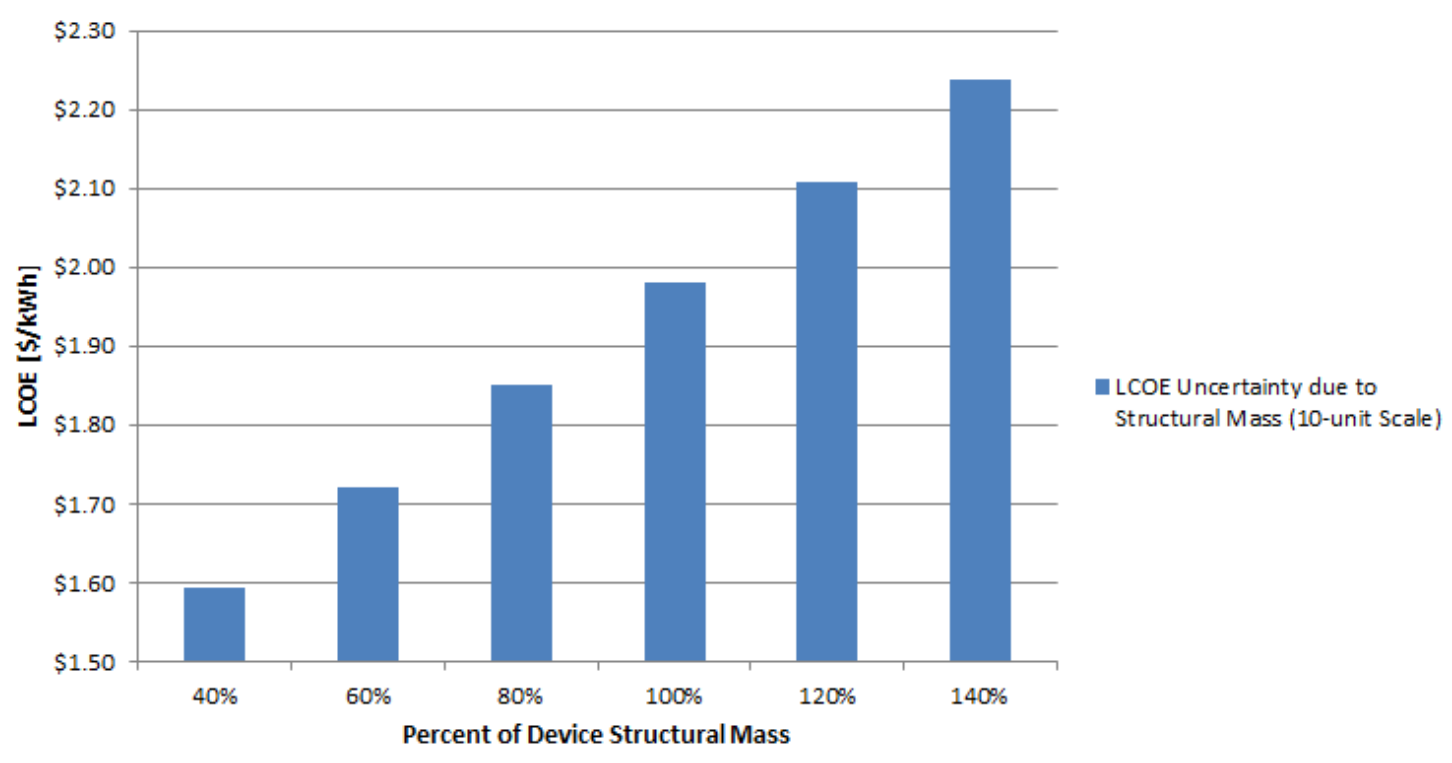

Figure 12: LCOE (cents/kWh) as a function of device structural mass. 


\section{Acknowledgment}

\section{References}

[1] V. Neary, M. Previsic, R. A. Jepsen, M. Lawson, Y.-H. Yu, A. Copping, A. Fontaine, K. Hallet, D. Murray, Methodology for Design and Economic Analysis of Marine Energy Conversion (MEC) Technologies, Sandia Report SAND2013-9040, Sandia National Laboratories (Mar. 2014).

2] D. Bull, C. Smith, D. S. Jenne, P. Jacob, A. Copping, S. Willits, A. Fontaine, D. Brefort, G. Copeland, M. Gordon, R. A. Jepsen, Reference Model 6 (RM6): Oscillating Water Column Device, SAND Report SAND2014-18311, Sandia National Laboratories (Sep. 2014).

[3] Y. Masuda, T. Yamazaki, Y. Outa, M. McCormick, Study of backward bent duct buoy, in: OCEANS '87, 1987, pp. 384-389. doi:10.1109/0CEANS.1987.1160750

[4] D. Bull, E. Johnson, Optimal resistive control strategy for a floating OWC device in: Proceedings of the 10 ${ }^{\text {th }}$ European Wave and Tidal Energy Conference, Technical Committee of the European Wave and Tidal Energy Conference, Aalborg, Denmark, 2013. URL http://energy.sandia.gov/wp/wp-content/gallery/uploads/SAND2013-6198c.pdf

[5] C. Smith, D. Bull, S. Willits, A. Fontaine, Optimization and average annual power predictions of a Backward Bent Duct Buoy oscillating water column device using a Wells Turbine, in: Proceedings of the 2nd Marine Energy Technology Symposium, Seattle, WA, USA, 2014.

[6] D. Bull, P. Jacob, Methodology for creating nonaxisymmetric WECs to screen mooring designs using a Morison Equation approach, in: OCEANS '12. 'Harnessing the Power of the Ocean'. Proceedings, Hampton Roads, VA, 2012 , pp. 1 -9. doi:10.1109/0CEANS.2012.6404870

[7] G. Copeland, D. Bull, R. A. Jepsen, M. Gordon, Oscillating Water Column Structural Model, SAND Report SAND201418082, Sandia National Laboratories (Sep. 2014).

[8] A. Copping, S. H. Geerlofs, The Contribution of Environmental Siting and Permitting Requirements to the Cost of Energy for Oscillating Water Column Wave Energy Devices: Reference Model \#6., Tech. Rep. PNNL-22723, Pacific Northwest National Laboratory (Nov. 2013).

395 [9] S. K. Chakrabarti, Hydrodynamics of offshore structures, WIT press, 1987.

[10] Veritas, Det Norske, Offshore Standard DNV-OS-E301 Position Mooring (Oct. 2008).

[11] J. C. Berg, Extreme ocean wave conditions for northern california wave energy conversion device, SAND 2011-9304, Sandia National Laboratories (2011).

[12] D. Brefort, D. Bull, Mooring Design for the Floating Oscillating Water Column Reference Model, SAND Report SAND2014-17817, Sandia National Laboratories (Sep. 2014).

[13] D. N. Veritas, Hull structural design ships with length 100 metres and above (2009). URL https://dspace.ist.utl.pt/bitstream/2295/108867/1/D

[14] D. Bull, Pneumatic Performance of a non-axisymmetric floating oscillating water column wave energy conversion device in random waves, in: Proceedings of the 2nd Marine Energy Technology Symposium, Seattle, WA, USA, 2014.

15] WAMIT, WAMIT User Manual, Chestnut Hill, MA, 7th Edition (2012) URL http://www.wamit.com/manual.htm

[16] D. Bull, An Improved Model of the Behaviors of Floating Structures with Moonpools: Theory and Application to Oscillating Water Column Devices, Ocean Engineering.

[17] D. Bull, B. Gunawan, B. Holmes, Experimental Confirmation of Water Column Natural Resonance Migration in a BBDB Device, SAND Report SAND2014-17816, Sandia National Laboratories (Aug. 2014).

18] S. Chakrabarti, Hydrodynamics of Offshore Structures, WIT Press, Boston, MA, 1987.

[19] L. M. C. Gato, A. F. O. Falcao, On the Theory of the Wells Turbine Journal of Engineering for Gas Turbines and Power 106 (3) (1984) 628-633. doi:10.1115/1.3239616 URL http://dx.doi.org/10.1115/1.3239616

[20] A. Brito-Melo, L. M. C. Gato, A. J. N. A. Sarmento, Analysis of Wells turbine design parameters by numerical simulation of the OWC performance, Ocean Engineering 29 (12)(2002) 1463-1477. doi:10.1016/S0029-8018(01)00099-3 URL http://www.sciencedirect.com/science/article/pii/S0029801801000993

21] L. M. C. Gato, M. Webster, An experimental investigation into the effect of rotor blade sweep on the performance of the variable-pitch Wells turbine, Proceedings of the Institution of Mechanical Engineers, Part A: Journal of Power and Energy 215 (5) (2001) 611-622. doi:10.1243/0957650011538848

URL http://pia.sagepub.com/content/215/5/611

[22] R. Starzmann, Aero-Acoustic Analysis of Wells Turbines for Ocean Wave Energy Conversion, pHD, Univertity of Siegen, Siegen, Germany (Mar. 2012). 
[23] T. Setoguchi, M. Takao, Current status of self rectifying air turbines for wave energy conversion, Energy Conversion and Management 47 (15-16) (2006) 2382-2396. doi:10.1016/j.enconman.2005.11.013

URL http://linkinghub.elsevier.com/retrieve/pii/S0196890405003158

[24] C. Smith, D. Bull, S. Willits, A. Fontaine, Optimization and Annual Average Power Predictions of a Backward Bent Duct Buoy Oscillating Water Column Device Using the Wells Turbine SAND Report SAND2014-1689R, Sandia National Laboratories (Jul. 2014).

URL https://vtechworks.lib.vt.edu/handle/10919/49192

[25] A. Falco, R. Rodrigues, Stochastic modelling of OWC wave power plant performance, Applied Ocean Research 24 (2) (2002) 59-71. doi:10.1016/S0141-1187(02)00022-6

URL http://www.sciencedirect.com/science/article/pii/S0141118702000226

[26] C. Burt, X. Piao, F. Gaudi, B. Busch, N. Taufik, Electric Motor Efficiency under Variable Frequencies and Loads, Journal of Irrigation and Drainage Engineering 134 (2) (2008) 129-136. doi:10.1061/(ASCE) 0733-9437(2008) 134:2(129) URL http://dx.doi.org/10.1061/(ASCE) 0733-9437(2008)134:2(129)

[27] U. S. D. of Energy, Adjustable speed drive part-load efficiency Tech. rep., Advanced Manufacturing Office. Energy Efficiency and Renewable Energy. (2012).

URL https://www . eere.energy.gov/manufacturing/tech_deployment/pdfs/motor_tip_sheet11.pdf

[28] T. Thorpe, A Review of Wave Energy Volume 2 Appendix, Tech. Rep. ETSU-R-72, Energy Technology Support Unit, Unitek Kingdom (Dec. 1992).

[29] A. Copping, S. H. Geerlofs, The Contribution of Environmental Siting and Permitting Requirements to the Cost of Energy for Marine and Hydrokenetic Devices: Reference Models \#1, \#2, and \#3. Tech. Rep. PNNL - 20963, Pacific Northwest National Laboratory (Nov. 2011).

445 URL http://www.re-vision.net/documents/RM1-3_EnvironmentalAssessment_PNNL.pdf

[30] A. LaBonte, P. OConnor, C. Fitzpatrick, K. Hallett, Y. Li, Standardized cost and performance reporting for marine and hydrokinetic technologies in: Proceedings of the 1st Marine Energy Technology Symposium, Washington DC, 2013.

URL http://www.globalmarinerenewable.com/images/standardized\%20cost\%20and\%20performance\%20reporting\% 20 or $\% 20$ marine $\% 20$ and $\% 20$ hydrokinetic\%20technologies.pdf

450 [31] Reference model website.

URL http://energy . sandia.gov/reference-model-project-rmp/ 